\title{
Social cohesion as perceived by community- dwelling older people: the role of individual and neighbourhood characteristics
}

\author{
By Hanna M. VAN DijK ${ }^{*}$ Jane M. CRAMM* $\mathcal{E}$ \\ ANNA P. NIEBOER*
}

\begin{abstract}
Social cohesion in neighbourhoods is critical to supporting the rising number of community-dwelling older people. Our aim was thus to identify individual and neighbourhood characteristics influencing social cohesion among older people. We employed a cross-sectional study of $945(66 \%$ response rate) community-dwelling older residents $(70+)$ in Rotterdam. To account for the hierarchical structure of the study design, we fitted a hierarchical random-effects model comprising 804 older people (level 1) nested in 72 neighbourhoods (level 2). Multilevel analyses showed that both individual (age, ethnic background, years of residence, income and self-rated health) and neighbourhood characteristics (neighbourhood security) affect social cohesion among community-dwelling older people. Results suggest that policy makers should consider such factors in promoting social cohesion among community-dwelling older people. Policies aimed at improving neighbourhood security may lead to higher levels of social cohesion.
\end{abstract}


International Journal of Ageing and Later Life

Keywords: social cohesion, older people, neighbourhood security, neighbourhood services, community, multilevel.

\section{Introduction}

In answer to the growing demands of ageing populations, governments increasingly promote community-based care rather than investing in costly institutional care (Anderson \& Hussey 2000; Sixsmith \& Sixsmith 2008). Although this tendency towards "ageing in place" is driven by a need to reduce health and social care costs, research findings show that older people also prefer to live at home for as long as possible (Heywood et al. 2002; Hooyman \& Kiyak 2008). Smaller social networks (McPherson et al. 2006; Oh \& Kim 2009) and declining mobility (Shaw et al. 2007) render community-dwelling older people more dependent on their neighbours for support (Campbell \& Lee 1992; Cannuscio et al. 2003; Forrest \& Kearns 2001; Gray 2009; Nocon \& Pearson 2000; Russell et al. 1998; Wiles 2005).

Governments across the western world increasingly invest in policies to promote social cohesion (Forrest \& Kearns 2001; Höhn 2005; Morrison 2003), which may be particularly important in supporting older people to live healthily and independently (Forrest \& Kearns 2001). In these debates, the neighbourhood is perceived as the key setting in fostering social cohesion (Forrest 2004; Forrest \& Kearns 2001; Kawachi \& Berkman 2003; Morrison 2003; Social Exclusion Unit 2001), especially for older people who spend a great proportion of their lives in the neighbourhood (Kellaher et al. 2004; Philips et al. 2005).

Social cohesion can be understood as patterns of social interaction among neighbours and the associated process of building shared values (Carpiano 2006; Fone et al. 2007; Kawachi \& Berkman 2000; Maxwell 1996). Neighbourhoods with high levels of social cohesion are expected to generate values such as familiarity, interpersonal trust and norms of reciprocity (Carpiano 2006; Fone et al. 2007), which may be beneficial to the health and well-being of community-dwelling older people. Research has led to an increasing awareness of the importance of social cohesion on both mental (Ellaway et al. 2001; Fone et al. 2007; Mair et al. 2010; O'Campo et al. 2009) and physical health outcomes (Browning \& Cagney 2002; Ellaway et al. 2001; Wolf \& Bruhn 1993). Kawachi and Berkman 
(2000) have argued that social cohesion contributes to better health through providing social support, adopting health-promoting behaviour, and facilitating access to services. Communities marked by high levels of social cohesion also mediate against the deleterious effects of stress (Rios et al. 2012) and adverse life events (Egolf et al. 1992), which has particular relevance for older people who are likely to face both (Hardy et al. 2002).

Although research supports the importance of social cohesion for health and well-being, we lack evidence on the predictors of neighbourhood social cohesion among community-dwelling older people. A few studies conducted among populations of all ages provide some insight, reporting higher levels of social cohesion among married (Farrell et al. 2003; Pampalon et al. 2007), older (Ellaway et al. 2001; Letki 2008; Pampalon et al. 2007; Skjaeveland \& Garling 1997; Wilkinson 2008) and more highly educated (Buckner 1988; Pampalon et al. 2007; Robinson \& Wilkinson 1995) people. For the population at large, research has consistently shown that residential stability exerts a positive influence on social cohesion (Buckner 1988; DiPasquale \& Glaeser 1999; Ellaway et al. 2001; Robinson \& Wilkinson 1995). Moreover, several studies demonstrated a relation between social cohesion and health outcomes. Whereas some studies argue that social cohesion contributes to positive health outcomes (Browning \& Cagney 2002; Ellaway et al. 2001; Kawachi \& Berkman 2000; Poortinga, Dunstan \& Fone 2007), other studies argue the opposite, showing that people with poor health reported lower social cohesion scores (Robinson \& Wilkinson 1995), presumably because their (physical) disabilities hinder establishing social relations and participation in neighbourhood activities (Paillard-Borg et al. 2009).

With respect to neighbourhood characteristics, several studies have reported that negative perceptions of neighbourhood security hinder social interaction among neighbours (Bellair 1997; Bursik \& Grasmick 1993; Liu 2011; Markowitz et al. 2001; Oh 2003; Sampson \& Raudenbush 1999) and inhibit social cohesion (Gibson et al. 2002; Saegert \& Winkel 2004; Sampson 1991; Ziersch et al. 2005). Conversely, the existence of sufficient neighbourhood services and facilities promotes interaction (Baum \& Palmer 2002; Flap \& Völker 2005; Peterson et al. 2000; Völker et al. 2007), which in turn is found to increase the level of social cohesion in the neighbourhood (van Bergeijk et al. 2008). 
International Journal of Ageing and Later Life

Even though neighbourhood social cohesion seems to be an important source of support for older people and may buffer negative health consequences of ageing, it has received surprisingly little research attention. Insight into what contributes to social cohesion among communitydwelling older people will provide policy makers with valuable knowledge on how to support independent living. This study aims to identify individual and neighbourhood characteristics for social cohesion among community-dwelling older people. In line with previous research (see e.g. Cummins et al. 2005; Pampalon et al. 2007), we thus consider both individual and contextual factors, which enables us to understand the role of the (social) environment in relation to social cohesion more thoroughly.

\section{Methods}

We disposed of a randomly selected recruitment sample of 1440 independently living older persons aged 70 and over from 72 neighbourhoods in four Rotterdam districts (Lage Land/Prinsenland, Lombardijen, Oude Westen and Vreewijk) in 2011. Neighbourhoods were defined on the basis of four-digit postal codes designated by the government. The sample comprised approximately 420 persons per district, proportional to neighbourhood and age group $(70-74 ; 75-79 ; 80$ $84 ; 85+)$, allowing us to account for different age groups within neighbourhoods.

Respondents were asked by mail to participate in the study by completing a written or online questionnaire. Respondents who did not respond first received a reminder by mail, then were reminded by telephone and finally, visited at home. All participants were rewarded with a 1/5 ticket in the Dutch State Lottery. Our final sample consisted of 945 respondents (66\% response rate). No differences were found in gender and age compared to the original sample $(n=1440)$. We did however find a small but significant difference in ethnic background; $17 \%$ had another ethnic background in our study sample, compared to $22 \%$ in the original sample. Ethical approval was provided by the ethics committee of the Erasmus University Medical Centre of Rotterdam in June 2011. A detailed description of our study design can be found in our study protocol (Cramm et al. 2011). 
Social cohesion among community-dwelling older people

\section{Measurements}

\section{Dependent Variable}

Our dependent variable was social cohesion in the neighbourhood. Following Fone and colleagues (2007), we used an eight-item instrument derived from Buckner (1988) to assess neighbourhood social cohesion. The measure covers feelings of trust, norms of reciprocity, and more tangible sources of support. Respondents were asked to assess their agreement (on a five-point scale ranging from "strongly disagree" (1) to "strongly agree" (5)) with the following statements: "I visit my neighbours in their homes"; "The friendships and associations I have with other people in my neighbourhood mean a lot to me"; "If I need advice about something I could go to someone in my neighbourhood"; "I believe my neighbours would help in an emergency"; "I borrow things and exchange favours with my neighbours"; "I would be willing to work together with others on something to improve my neighbourhood"; "I rarely have a neighbour over to my house to visit" (reverse coded); and "I regularly stop and talk with people in my neighbourhood." By summing the responses to these eight questions with equal weighting (mean: 24.39; standard deviation (SD): 5.38), we derived a social cohesion score (range: 8-39) with higher scores indicating higher levels of social cohesion. The Cronbach's alpha (0.75) of the score demonstrated reliability.

\section{Individual-Level Indicators}

We employed different individual characteristics relevant to an analysis of social cohesion: gender, age (measured in years), marital status (coded as a dummy variable), and ethnic background (country of birth). We included education and income as indicators of socioeconomic status. The first was measured by highest educational achievement on a seven-point scale ranging from 1 (primary school or less) to 7 (university degree). Net monthly income (including social benefits, pensions and salaries) was measured on a five-point scale ranging from 1 (€1000) to 5 (>€3050) divided by the number of household members. We asked for home ownership (owner versus renter) and established years of residence at the current address in five prescribed categories: $<1$ year (1), between 1 and 3 
International Journal of Ageing and Later Life

years (2), between 3 and 7 years (3), between 7 and 15 years (4), and $\geq 15$ years (5).

Finally, we measured self-rated health with the question: "How would you describe your overall state of health these days? Would you say it is (5) excellent, (4) very good, (3) good, (2) fair, or (1) poor?". This measure is considered a valid and robust measure of general health status; previous studies demonstrate that self-rated health has high predictive validity for objective health measures such as mortality, physical disability and chronic disease status (Idler \& Benyamanini 1997; Idler \& Kasl 1995; Mossey \& Shapiro 1982).

\section{Neighbourhood-Level Indicators}

Two explanatory variables on the neighbourhood level were included in our analysis: neighbourhood services and neighbourhood security. Neighbourhood services and neighbourhood security are examples of shared neighbourhood level characteristics. Therefore, both neighbourhood characteristics were aggregated from individual level variables. We measured them by using two dimensions of the Neighbourhood Quality Index (Yang et al. 2002). We assessed adequacy of neighbourhood services and facilities by asking respondents how strongly they agreed with the following statements: "The neighbourhood has adequate lighting"; "The neighbourhood has convenient transportation"; and "The neighbourhood has adequate public facilities." Responses to these items were structured on a four-point Likert-scale ranging from total disagreement (1) to total agreement (4). The adequacy of services score was derived by summing the responses to each item and aggregating them to the neighbourhood level. The Cronbach's alpha of the neighbourhood services scale was 0.65 .

We assessed perceived neighbourhood security by using responses to the following statements: "The neighbourhood is quiet and peaceful"; "The neighbourhood is spacious and roomy"; "The neighbourhood is safe"; and "The neighbourhood is orderly, with good public security." Responses were structured on a four-point Likert-scale ranging from total disagreement (1) to total agreement (4). A score was derived by summing the responses to each item and aggregating them to the neighbourhood level. The Cronbach's alpha of the scale was 0.83 , indicating good reliability. 
Social cohesion among community-dwelling older people

\section{Analysis}

We employed descriptive statistics and used univariate analyses (indicated by the Pearson's R) to assess the relationship between social cohesion and individual characteristics (gender, age, marital status, ethnic background, home ownership, years of residence, education, income and health).

First, we tested for the influence of the neighbourhood (level 2) on social cohesion. The results indicated that the neighbourhood did affect social cohesion ( -2 loglikelihood 5650.082 vs. 5644.360: $p \leq 0.05$ ). Moreover, we also checked for clustering in neighbourhoods for security and services scores and found that the neighbourhood affects both security $(-2$ loglikelihood 4031.641 vs. 3981.478: $p \leq 0.01)$ and services $(-2$ loglikelihood 3333.226 vs. 3322.560: $p \leq 0.01$ ). Therefore, we fitted a hierarchical random-effects model to account for the hierarchical structure of the study design.

We also checked for a three-level structure of the district level (level 3). Because these results indicated that district level did not affect social cohesion ( -2 loglikelihood 5650.082), we used the two-level structure. The structure comprised 945 older people (level 1) nested in 72 neighbourhoods (level 2). Individuals were excluded when observations were missing for any outcome, leading to the inclusion of 804 people in our multilevel analysis. In view of the comparability of our findings, we standardised all of the independent variables.

We employed a two-level model (using maximum likelihood estimation) to examine the predictive role of individual- and neighbourhood-level indicators on social cohesion. The analyses were performed by multilevel linear regression analysis with a stepwise inclusion of the group of individual variables in model 3, neighbourhood services in model 4, and finally, neighbourhood security in model 5. Statistical Package for the Social Sciences (SPSS) software (version 17.0; SPSS Inc., Chicago, IL, USA) was used for all statistical analyses.

\section{Results}

Table 1 provides descriptive statistics for the independent variables and social cohesion. Respondents were mostly female $(57 \%)$, had an average age of 77.5 (range: 70-101; SD: 5.8), and were married in about one-third 
International Journal of Ageing and Later Life

Table 1. Descriptive statistics

\begin{tabular}{lcc}
\hline Demographic characteristics & Range & $\%$ or mean (SD) \\
\hline Gender (female) & & $57 \%$ \\
Age (years) & $70-101$ & $77.5(5.8)$ \\
Marital status (married) & & $35 \%$ \\
Ethnic background (Dutch) & & $83 \%$ \\
Home ownership (owner) & $1-5$ & $19 \%$ \\
Years of residence & & $4.34(0.99)$ \\
$\quad<1$ year & & $2 \%$ \\
$1-3$ years & & $6 \%$ \\
$3-7$ years & & $9 \%$ \\
$7-15$ years & & $22 \%$ \\
$\quad \geq 15$ years & $1-7$ & $61 \%$ \\
Education & $1-5$ & $3.97(1.70)$ \\
Income & $1-5$ & $2.18(1.04)$ \\
Health & $8.75-14$ & $2.65(0.95)$ \\
Neighbourhood security & $7.5-12$ & $11.4(0.95)$ \\
Neighbourhood services & $8-39$ & $8.94(0.51)$ \\
Social cohesion & $24.39(5.38)$ \\
\hline
\end{tabular}

(35\%) of the cases. A vast majority was born in the Netherlands (83\%) and had lived $\geq 7$ years at their current address (83\%), indicating residential stability (Ross et al. 2000).

Univariate analysis of the associations between individual-level indicators and social cohesion are presented in Table 2. Respondents' age $(p \leq 0.05)$, ethnic background $(p \leq 0.01)$, home ownership $(p \leq 0.01)$, education $(p \leq 0.01)$, income $(p \leq 0.001)$ and self-rated health $(p \leq 0.01)$ were significantly related to social cohesion. No significant correlations were found between social cohesion and gender, marital status, or years of residence.

Table 3 presents the results of the multilevel regression analysis. Looking at the individual characteristics in the final full model (5), age appeared to be negatively associated with social cohesion $(p \leq 0.01)$. In addition, we found significant positive relations between social cohesion and Dutch background $(p \leq 0.05)$, years of residence $(p \leq 0.05)$, income $(p \leq 0.05)$ and self-rated health $(p \leq 0.05)$. Years of residence $(p \leq 0.05)$ became significant once neighbourhood variables were included in the model (model 4 and 5). 
Social cohesion among community-dwelling older people

Table 2. Associations among individual characteristics and social cohesion (r)

\begin{tabular}{lcc}
\hline & Social cohesion & $n$ \\
\hline Gender (female) & 0.03 & 911 \\
Age & $-0.07^{*}$ & 911 \\
Marital status (married) & 0.02 & 911 \\
Ethnic background (Dutch) & $0.10^{* *}$ & 911 \\
Home ownership (owner) & $0.11^{* *}$ & 911 \\
Years of residence & 0.05 & 906 \\
Education (1-7) & $0.11^{* *}$ & 890 \\
Income (1-5) & $0.15^{* * *}$ & 822 \\
Health & $0.10^{* *}$ & 905 \\
\hline
\end{tabular}

${ }^{* * *} p \leq 0.001 ;{ }^{* *} p \leq 0.01 ;{ }^{*} p \leq 0.05$ (two-tailed).

Gender, marital status, home ownership, and education were not significantly associated with social cohesion in our study population. Besides the individual-level indicators, neighbourhood security appeared to be important for social cohesion $(p \leq 0.01)$. Adequacy of neighbourhood services was only found to be significant in model 4 ( $p \leq 0.01)$, but lost significance once neighbourhood security entered the equation in model 5 .

The intra-class correlation (ICC $=0.03$ ) showed that $3 \%$ of the total individual differences in older people's perceptions of social cohesion occurred at the neighbourhood level and might be attributable to contextual factors.

\section{Discussion}

In order to support growing populations of community-dwelling older people to live independently, social cohesion in the neighbourhood becomes increasingly important. Whereas research to date has tended to focus on the effects of social cohesion on health and was limited to younger populations, this multilevel study enhances our understanding of both individual and neighbourhood characteristics that contribute to social cohesion among older people in the neighbourhood.

The mean social cohesion score in this study (24.39 \pm 5.38 ; range 8-39) was significantly lower than that reported by Fone and colleagues (2007) 
International Journal of Ageing and Later Life

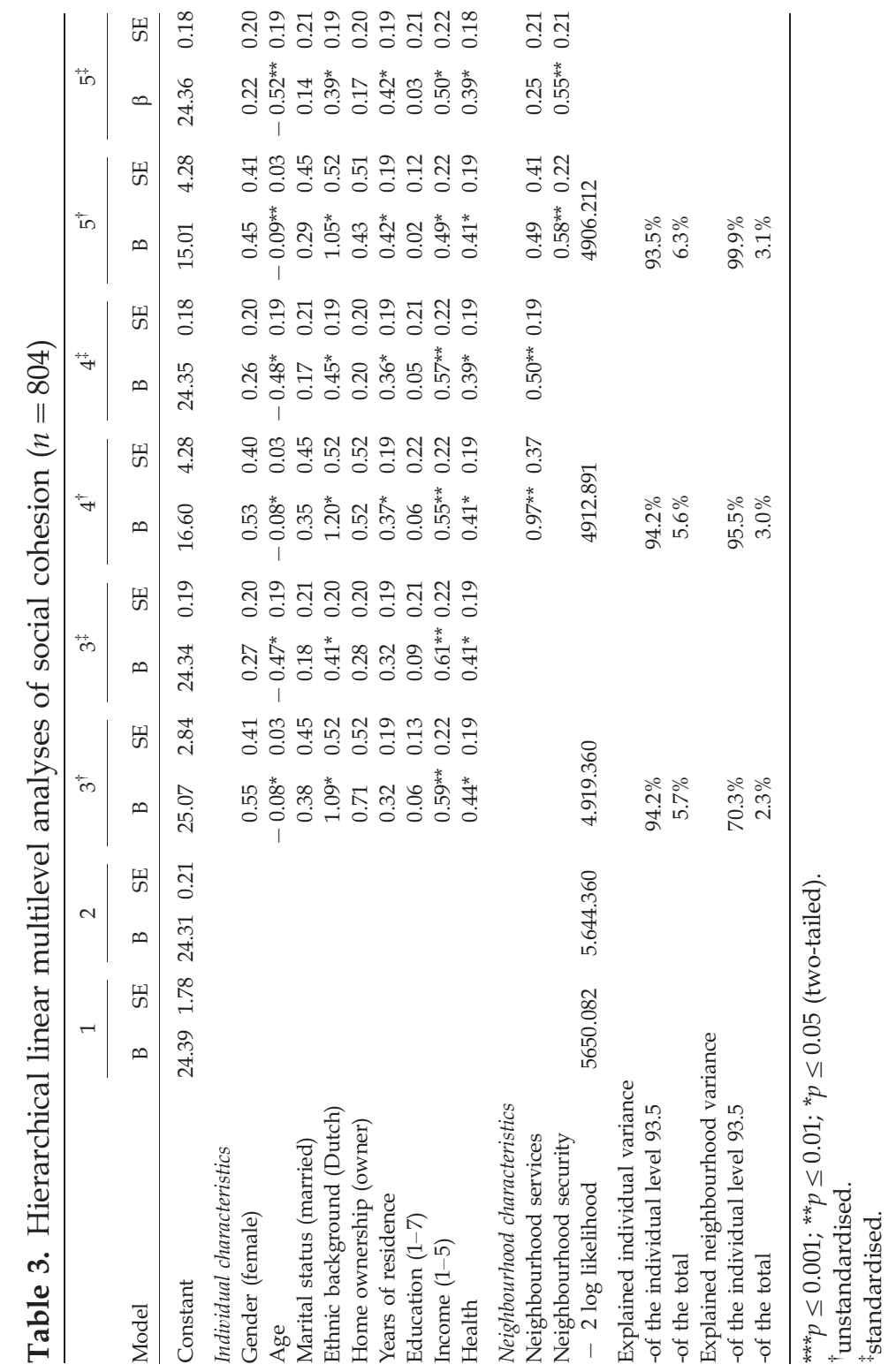


(29.2 \pm 5.5 ; range $8-40)$, which might be explained by the studies' respective samples: older people $(70+)$ living in a metropolitan area (our study) versus 18-74-year-olds residing in a provincial town (Fone et al. 2007). Although previous studious among younger populations demonstrated that social cohesion is positively associated with age (Ellaway et al. 2001; Letki 2008; Pampalon et al. 2007), our multilevel analysis indicates that from a certain age upwards $(70+)$ age may actually inhibit social cohesion. This finding may be explained by the fact that older people are increasingly faced with cognitive impairments and physical disabilities that hinder engagement in social activities (Paillard-Borg et al. 2009). Furthermore, older people are especially vulnerable to having fewer social network ties and less social interaction (McPherson et al. 2006; Oh \& Kim 2009).

Consistent with previous research (Almeida et al. 2009; Buckner 1988; Ellaway et al. 2001; Obst et al. 2002; Prezza et al. 2001; Robinson \& Wilkinson 1995), our study showed a positive association between residential stability and social cohesion. However, this association was only found when we accounted for neighbourhood characteristics in the analysis. This finding may suggest that the relationship between residential stability and social cohesion is strengthened by neighbourhood characteristics such as the adequacy of services and security in the neighbourhood. As indicated in prior studies, length of residence enables social relationships to develop and strengthens community attachment (Bridge 1994; Goudy 1990; Sampson 1988, 1991), leading in turn to higher levels of social cohesion (Wilkinson 2008). However, to allow residential stability among older people, there is an increasing need for governments to invest in appropriate and affordable long-term housing (Davey 2006). However, given our finding that social cohesion decreases from a certain age upwards (among people aged $70+$ and over), governments should consider an age mix in the neighbourhood when building long-term housing. Previous research supports that older people prefer an age-mix in the neighbourhood (Gabriel \& Bowling 2004). Governments may manage to attain an age mix through combining a variety of houses and services that suit both the needs of younger and older people (Morris et al. 2012; Thang 2001). Moreover, governments would be well advised to invest in regulations that allow second units to be built on the property of (single) family dwellings. Research shows that current regulations now often restrict 
International Journal of Ageing and Later Life

older people from living near their children and grandchildren (Rosenberg \& Everitt 2001).

Our multilevel analysis demonstrated no relation between home ownership and social cohesion; in line with previous research (DiPasquale \& Glaeser 1999), the influence of home ownership on social cohesion may diminish or disappear when accounting for length of residence.

Our analysis revealed that self-rated health was associated with social cohesion, most likely because people in poor health are less able to establish social connections and participate in neighbourhood activities (Mulvaney-Day et al. 2007; Robinson \& Wilkinson 1995). Policy makers may target interventions toward engaging older people with poor health, which will allow them to participate in the neighbourhood in spite of their (physical) impairments.

Furthermore, the results demonstrated an association between ethnic background and social cohesion. In line with previous research among younger populations (Curley 2010; Dekker \& Bolt 2005), ethnic minority groups are found to have fewer social contacts with their neighbours and tend to focus on their own ethnic group for social contact. Since three out of four districts in our study comprise a large majority of Dutch neighbours, the likelihood of being surrounded by non-Dutch co-ethnics is low, which may constrain social cohesion among these groups.

Moreover, we found a positive relation between a higher income and social cohesion. This contrasts previous studies among younger populations that report lower cohesion scores for higher income people (Obst et al. 2002; Robinson \& Wilkinson 1995), which is mostly explained by the fact that affluent people can afford (travel) costs that allow them to maintain social contact outside the neighbourhood (Musterd \& Ostendorf 1998). However, given older people's declining health and limited mobility, older people are more reliant on their neighbourhood for social contact (Shaw et al. 2007). Therefore, income may provide older people with financial resources to participate in neighbourhood activities, enabling them to maintain their social network within the neighbourhood (Scharf et al. 2004). This finding may highlight the need for policy-makers to invest in affordable social activities.

Unlike previous research, we did not find any evidence that gender (Glynn 1981) or marital status (Farrell et al. 2003; Prezza et al. 2001) 
predicted social cohesion among older people. This could indicate that, with age, differences between such socio-demographic indicators tend to diminish or become less decisive in explaining social cohesion. For example, the higher social cohesion scores that were reported among women (Farrell et al. 2003; Prezza et al. 2001) may be due to their larger amount of time spent in the neighbourhood. However, with rising age, women and men spend an equal amount of time in the neighbourhood (Horgas et al. 1998). Likewise, although previous studies among populations of all ages reported higher social cohesion scores among married people, both married and nonmarried or widowed older people $(70+)$ may rely on previously established relationships with neighbours. The high level of residential stability we found among older people does provide evidence for this finding.

This multi-level study enabled us to demonstrate that over and above individual characteristics, neighbourhood characteristics affect social cohesion scores among community-dwelling older people. This study stresses the importance of positive perceptions of neighbourhood security for social cohesion, a finding that policy makers should heed. Next to improving objective security, which is often done through the identification and adaptation of physical features (such as street lighting) that may provide opportunities for crime (Lorenc et al. 2012; Welsh \& Farrington 2008), policy makers should try to increase perceptions of security, which are found to represent an independent psychological dimension (Farrall et al. 2007; Lindström et al. 2003). They could target interventions toward engaging older people in voluntary associations and local decision-making processes, both of which positively relate to feelings of security and social cohesion (Laurence \& Heath 2008; Lee 1983).

In accordance with previous research (van Bergeijk et al. 2008), our multilevel analysis demonstrated an association between neighbourhood services and social cohesion among older people. However, this effect disappeared once neighbourhood security was added to the model. This may indicate that neighbourhood security acts as a mediator between neighbourhood services and social cohesion; a finding that further stresses the importance of improving neighbourhood security. Moreover, our operationalisation of neighbourhood services may have been too limited. For example, we did not account for the proximity and use of (recreation) facilities, such as grocery stores and parks, which are found to act as meeting 
International Journal of Ageing and Later Life

places (Völker et al. 2007), affecting social cohesion scores (van Bergeijk et al. 2008).

We should note some other limitations. Although this multilevel study enhances our understanding of both individual and neighbourhood level characteristics, the results were based on cross-sectional data, which limits the possibility of demonstrating causality. And, whereas our data indicated that feelings of security increase social cohesion, a large body of research has revealed that social cohesion diminishes feelings of insecurity and crime (e.g. Baum et al. 2009 and Putnam 2000). Likewise, our study showed that poor health status was negatively associated with social cohesion, which in turn may further affect health. Such a pattern of findings indicates that social cohesion, health, and security are dynamic social processes that affect each other in a reciprocal manner. Since older people $(70+)$ report lower levels of social cohesion, report a higher sense of insecurity (de Donder et al. 2005), and are likely to experience illness and stressful life events (Hardy et al. 2002), further research to disentangle the interplay between these processes is particularly relevant for this group. Another limitation was that we had to exclude 141 individuals from our multilevel analysis due to missing observations for any outcome. We checked whether the 804 respondents differed from those with complete data and found no differences for ethnic background and age, but a small difference regarding gender. Given that we found no association between gender and social cohesion in our univariate analysis, we do not think this has affected our findings. Last, the selective nonresponse (i.e. the difference between our randomly selected recruitment sample and study sample) among people with another ethnic background should be noted. Lower response rates among ethnic minorities are common across Western countries (Eisner \& Ribeaud 2007; Feskens et al. 2006), especially in urban areas (Feskens et al. 2007). Although we do not think the marginal underrepresentation of people with another ethnic background has affected our ability to gain insight in important individual and neighbourhood characteristics for social cohesion, future research may pay specific attention to social cohesion among older people with another ethnic background.

\section{Conclusion}

Our study contributed to our understanding of social cohesion among community-dwelling older people. Since research has indicated that 
neighbourhood social cohesion enhances both the health (Ellaway et al. 2001 and Kawachi \& Berkman 2000) and well-being (Cramm et al. 2012) of older people, this study provides policy makers with valuable information on generating more social cohesion among the growing population of community-dwelling older people. Our analysis clearly showed that over and above individual (age, ethnic background, years of residence, income and self-rated health) characteristics, neighbourhood characteristics (neighbourhood security) are beneficial to social cohesion among older people in the community. We trust that these are interesting findings for policymakers, governments and municipalities aiming to promote social cohesion in neighbourhoods. To enable residential stability and in turn social cohesion among older people, consideration needs to be given to appropriate and affordable long-term housing that protects older people from being forced to move. Furthermore, given our finding that people with an older age (among people aged $70+$ ), a non-Dutch background, lower income and poor self-rated health reported lower social cohesion scores, policy makers may pay specific attention to these groups in promoting social cohesion. Moreover, the improvement of security in neighbourhoods is an advisable policy goal for the enhancement of social cohesion. Last, our multilevel study prompts future research to account for the neighbourhood context when studying social cohesion among older people.

\section{Corresponding Author}

Hanna M. van Dijk, Institute of Health Policy and Management, Erasmus University Rotterdam, Burgemeester Oudlaan 50, 3000 DR Rotterdam, The Netherlands. Email: hanna.vandijk@bmg.eur.nl

\section{References}

Almeida, J., Kawachi, I., Molnar, B. \& Subramanian, S. (2009). A multilevel analysis of social ties and social cohesion among Latinos and their neighbourhoods: Results from Chicago. Journal of Urban Health 86: 745-759.

Anderson, G. F. \& Hussey, P. S. (2000). Population aging: A comparison among industrialized countries. Health Affairs 19: 191-203. 
International Journal of Ageing and Later Life

Baum, F. \& Palmer, C. (2002). 'Opportunity structures': Urban landscape, social capital and health promotion in Australia. Health Promotion International 17: 351-361.

Baum, F., Ziersch, A., Zhang, G. \& Osborne, K. (2009). Do perceived neighbourhood cohesion and safety contribute to neighbourhood differences in health? Health \& Place 15: 925-934.

Bellair, P. E. (1997). Social interaction and community crime: Examining the importance of neighbour networks. Criminology 35: 577-703.

Bridge, G. (1994). Gentrification, class and residence: A reappraisal. Environment and Planning D: Society and Space 12: 31-51.

Browning, C. \& Cagney, K. (2002). Neighbourhood structural disadvantage, collective efficacy, and self-rated physical health in an urban setting. Journal of Health $\mathcal{E}$ Social Behavior 43(4): 383-399.

Buckner, J. C. (1988). The development of an instrument to measure neighbourhood cohesion. American Journal of Community Psychology 16: 771-791.

Bursik, R. J., Jr. \& Grasmick, H. G. (1993). Neighbourhoods and Crime: The Dimensions of Effective Community Control. New York: Lexington.

Campbell, K. E. \& Lee, B. A. (1992). Sources of personal neighbour networks: Social integration, need, or time? Social Forces 70: 77-100.

Cannuscio, C., Block, J. \& Kawachi, I. (2003). Social capital and successful aging: The role of senior housing. Annals of Internal Medicine 139: 395-400.

Carpiano, R. (2006). Towards a neighbourhood resource based theory of social capital for health: Can Bourdieu and sociology help? Social Science \& Medicine 62(1): 165-175.

Cramm, J. M., van Dijk, H., Lötters, F., van Exel, J. \& Nieboer, A. P. (2011). Evaluating an integrated neighbourhood approach to improve the well-being of frail elderly in a Dutch community: A study protocol. BMC Research Notes 4: 532-541.

Cramm, J. M., van Dijk, H. M. \& Nieboer, A. P. (2012). The importance of neighbourhood social cohesion and social capital for the wellbeing of older adults in the community. The Gerontologist 53(1): 142-152.

Cummins, S., Stafford, M., Macintyre, S., Marmot, M. \& Ellaway, A. (2005). Neighbourhood environment and its association with self-rated health: 
Evidence from Scotland and England. Journal of Epidemiology and Community Health 59(3): 207-213.

Curley, A. M. (2010). Relocating the poor: Social capital and neighbourhood resources. The Journal of Urban Affairs 32(1): 79-103.

Davey, J. (2006). "Ageing in place": The views of older homeowners on maintenance, renovation and adaptation. Social Policy Journal of New Zealand 27: 128-141.

De Donder, L., Verté, D. \& Messelis, E. (2005). Fear of crime and the elderly: Key-factors that determine fear of crime among elderly people in West Flanders. Ageing International 30(4): 363-376.

Dekker, K. \& Bolt, G. (2005). Social cohesion in post-war estates in the Netherlands: Differences between socioeconomic and ethnic groups. Urban Studies 42(13): 2447-2770.

DiPasquale, D. \& Glaeser, E. (1999). Incentives and social capital. Are home-owners better citizens? Journal of Urban Economics 45(2): 354-384.

Egolf, B., Lasker, J., Wolf, S. \& Potvin, L. (1992). The Roseto effect: A 50year comparison of mortality rates. American Journal of Public Health 82: 1089-1092.

Eisner, M. \& Ribeaud, D. (2007). Conducting a criminological survey in a culturally diverse context: Lessons from the Zurich Project on the social development of children. European Journal of Criminology 4: 271-298.

Ellaway, A., Macintyre, S. \& Kearns, A. (2001). Perceptions of place and health in socially contrasting neighbourhoods. Urban Studies 38(12): 2299-2316.

Farrall, S., Gray, E. \& Jackson, J. (2007). Theorising the Fear of Crime: The Cultural and Social Significance of Insecurities about Crime. Experience and Expression in the Fear of Crime Working Paper 5. Staffordshire \& London: Keele University \& London School of Economics.

Farrell, S. J., Aubry, T. \& Coulombe, D. (2003). Neighbourhoods and neighbours: Do they contribute to personal well-being? Journal of Community Psychology 32: 9-25.

Feskens, R. C. W., Hox, J., Lensvelt-Mulders, G. \& Schmeets, H. (2006). Collecting data among ethnic minorities in an international perspective. Field Methods 18: 284-304. 
International Journal of Ageing and Later Life

Feskens, R. C. W., Hox, J., Lensvelt-Mulders, G. \& Schmeets, H. (2007). Nonresponse among ethnic minorities: A multivariate analysis. Journal of Official Statistics 23(3): 387-408.

Flap, H. D. \& Völker, B. G. M. (2005). Gemeenschap, informele controle en collectieve kwaden in de buurt [Community, informal control and collective evils in the neighbourhood]. In B. G. M. Völker (ed.), Burgers in de buurt [Citizens in the neighbourhood] (pp. 41-67). Amsterdam: Amsterdam University Press.

Fone, D., Dunstan, F., Lloyd, K., Williams, G., Watkins, J. \& Palmer, S. (2007). Does social cohesion modify the association between area income deprivation and mental health? A multilevel analysis. International Journal of Epidemiology 36(2): 338-345.

Forrest, R. (2004). Who Cares About Neighbourhoods? (CNR Paper 26). Bristol: Centre for Neighbourhood Research.

Forrest, R. \& Kearns, A. (2001). Social cohesion, social capital and the neighbourhood. Urban Studies 38(12): 2125-2143.

Gabriel, Z. \& Bowling, A. (2004). Quality of life from the perspectives of older people. Ageing \& Society 24: 675-691.

Gibson, C. L., Zhao, J., Lovrich, N. P. \& Gaffney, M. J. (2002). Social integration, individual perceptions of collective efficacy, and fear of crime in three cities. Justice Quarterly 19: 537-556.

Gray, A. (2009). The social capital of older people. Ageing \& Society 29: 5-31.

Glynn, T. J. (1981). PSOC: Measurement and application. Human Relations 34: 780-818.

Goudy, W. (1990). Community attachment in a rural region. Rural Sociology 55(2): 178-198.

Hardy, S. E., Concato, J. \& Gill, T. M. (2002). Stressful life events among community-living older persons. Journal of General Internal Medicine 17(11): 832-838.

Heywood, F., Oldman, C. \& Means, R. (2002). Housing and Home in Later Life. Buckingham: Open University Press.

Höhn, C. (2005). Demographic challenges for social cohesion: a review and analysis of the work of the European Population Committee 2001-2004. Belgium: Council for Europe Publishing. 
Hooyman, N. R. \& Kiyak, H. A. (2008). Social Gerontology: A Multidisciplinary Perspective. Boston: Allyn and Bacon.

Horgas, A. L., Wilms, H. \& Baltes, M. M. (1998). Daily life in very old age: Everyday activities as expression of successful living. The Gerontologist 38: 556-568.

Idler, E. L \& Benyamanini, Y. (1997). Self-rated health and mortality: A review of twenty-seven community studies. Journal of Health and Social Behavior 38: 21-37.

Idler, E. L. \& Kasl, S. V. (1995). Self-ratings of health: Do they predict change in functional ability? Journals of Gerontology Series B: Psychological Sciences and Social Sciences 50: 344-353.

Kawachi, I. \& Berkman, L. F. (2000). Social cohesion, social capital and health. New York: Oxford University Press.

Kawachi, I. \& Berkman, L. F. (2003). Neighbourhoods and Health. New York: Oxford University Press.

Kellaher, L., Peace, S. \& Holland, C. (2004). Environment, identity and old age - quality of life or a life of quality? In A. Walker \& C. H. Hennessy (eds.), Growing Older: Quality of Life in Older Age (pp. 60-80). Maidenhead: Open University Press.

Laurence, J. \& Heath, A. (2008). Predictors of community cohesion: Multi-level modelling of the 2005 Citizenship Survey. London: Communities and Local Government.

Lee, J. (1983). Innovative Community Development. Seoul: Institute of Saemaul Undong Studies.

Letki, N. (2008). Does diversity Erode social cohesion? Social capital and race in British neighbourhoods. Political Studies 56: 99-126.

Lindström, M., Merlo, J. \& Östergren, P-O. (2003). Social capital and sense of insecurity in the neighbourhood: A population-based multilevel analysis in Malmö, Sweden. Social Science \& Medicine 56(5): $1111-1120$.

Liu, J. (2011). Functions of Crimes. Beijing: People's Publishing House.

Lorenc, T., Clayton, S., Neary, D., Whitehead, M., Petticrew, M., Thomson, H., Cummins, S., Sowden, A. \& Renton, A. (2012). Crime, fear of crime, environment, and mental health and wellbeing: Mapping review of theories and causal pathways. Health \& Place 18: 757-765. 
International Journal of Ageing and Later Life

Mair, C., Roux, A. D. \& Morenoff, J. (2010). Neighbourhood stressors and social support as predictors of depressive symptoms in the Chicago Community Adult Health Study. Health \& Place 16(5): 811-819.

Markowitz, F. E., Bellair, P. E., Allen, E. L. \& Jianhong, H. L. (2001). Extending social disorganization theory: Modelling the relationships between cohesion, disorder, and fear. Criminology 39: 293-320.

Maxwell, J. (1996). Social Dimensions of Economic Growth. Eric John Hanson Memorial Lecture Series, Volume 8. Edmonton, Canada: University of Alberta.

McPherson, M., Smith-Loving, L. \& Brashears, M. E. (2006). Social isolation in America: Changes in core discussion networks over two decades. American Sociological Review 71: 353-375.

Morris, A., Jamieson, M. \& Patulny, R. (2012). Is social mixing of tenures a solution for public housing estates? Evidence Base 1: 1-21.

Morrison, N. (2003). Neighbourhoods and social cohesion: Experiences from Europe. International Planning Studies 8(2): 115-138.

Mossey, J. M. \& Shapiro, E. (1982). Self-rated health: A predictor of mortality among the elderly. American Journal of Public Health 72: 800-808.

Mulvaney-Day, N. E., Alegría, M. \& Sribney, W. (2007). Social cohesion, social support and health among Latinos in the United States. Social Science \& Medicine 64(2): 477-495.

Musterd, S. \& Ostendorf, O. (1998). Urban Segregation and the Welfare State. London and New York: Routledge.

Nocon, A. \& Pearson, M. (2000). The roles of friends and neighbours in providing support for older people. Ageing \& Society 20(3): 341-367.

Obst, P., Smith, S. G. \& Zinkiewicz, L. (2002). An exploration of sense of community, Part 3: Dimensions and predictors of psychological sense of community in geographical communities. Journal of Community Psychology 30: 119-133.

O'Campo, P., Salmon, C. \& Burke, J. (2009). Neighbourhoods and mental well-being: What are the pathways? Health $\mathcal{E}$ Place 15(1): 5-68.

Oh, J-H. (2003). Assessing the social bonds of elderly neighbours: The role of length of residence, crime victimization, and perceived disorder. Sociological Inquiry 73(4): 490-510. 
Oh, J-H. \& Kim, S. (2009). Aging, neighbourhood attachment, and fear of crime: Testing reciprocal effects. Journal of Community Psychology 37(1): 21-40.

Paillard-Borg, S., Fratiglioni, L., Winblad, B. \& Wang, H. X. (2009). Leisure activities in late life in relation to dementia risk: Principal component analysis. Dementia and Geriatric Cognitive Disorders 28: 136-144.

Pampalon, R., Hamel, D., De Koninck, M. \& Disant, M. J. (2007). Perception of place and health: Differences between neighbourhoods in the Québec City region. Social Science \& Medicine 65(1): 95-111.

Peterson, R. D., Krivo, L. J. \& Harris, M. A. (2000). Disadvantage and neighbourhood violent crime. Do local institutions matter? Journal of Research in Crime and Delinquency 37(1): 31-63.

Philips, D. R., Siu, O.-L, Yeh, A. G.-O. \& Cheng, K. H. C. (2005). Ageing and the urban environment. In G. J. Andrews \& D. R. Philips (eds.), Ageing and Place (pp. 147-163). Abingdon: Routledge.

Poortinga, W., Dunstan, F. D. \& Fone, D. L. (2007). Perceptions of the neighbourhood environment and self rated health: A multilevel analysis of the Caerphilly Health and Social Needs Study. BMC Public Health 7: 285.

Prezza, M., Amici, M., Roberti, T. \& Tedeschi, G. (2001). Sense of community referred to the whole town: Its relations with neighbouring, loneliness, life satisfaction, and area of residence. Journal of Community Psychology 29(1): 29-52.

Putnam, R. (2000). Bowling Alone: The Collapse and Revival of American Community. New York: Simon and Schuster.

Rios, R., Aiken, L. S. \& Zautra, A. J. (2012). Neighbourhood contexts and the mediating role of neighbourhood social cohesion on health and psychological distress among Hispanic and Non-Hispanic Residents. Annals of Behavioral Medicine 43(1): 50-61.

Robinson, D. \& Wilkinson, D. (1995). Sense of community in a remote mining town: Validating a neighbourhood cohesion scale. American Journal of Community Psychology 23(1): 137-148.

Rosenberg, M. \& Everitt, J. (2001). Planning for aging populations: Inside or outside the walls. Progress in planning 56(3): 119-168.

Ross, C. E., Reynolds, J. R. \& Geis, K. J. (2000). The contingent meaning of neighbourhood stability for residents' psychological well-being. American Sociological Review 65: 581-597. 
International Journal of Ageing and Later Life

Russell, C., Hill, B. \& Basser, M. (1998). Older people's lives in the inner city: Hazardous or rewarding? Australian and New Zealand Journal of Public Health 22: 98-106.

Saegert, S. \& Winkel, G. (2004). Crime, social capital and community participation. American Journal of Community Psychology 34: 219-233.

Sampson, R. J. (1988). Local friendship ties and community attachment in mass society: A multilevel systemic model. American Sociological Review 53: 766-779.

Sampson, R. J. (1991). Linking the micro- and macrolevel dimensions of community social organization. Social Forces 70(1): 43-64.

Sampson, R. J. \& Raudenbush, S. W. (1999). Systematic social observation of public spaces: A new look at disorder in urban neighbourhoods. American Journal of Sociology 105: 603-651.

Scharf, T., Phillipson, C. \& Smith, A. E. (2004). Poverty and social exclusion: Growing older in deprived urban neighbourhoods. In A. Walker \& C. H. Hennessy (eds.), Growing Older: Quality of Life in Old Age (pp. 81-106). Maidenhead: Open University Press.

Shaw, B. A., Krause, N., Liang, J. \& Bennett, J. (2007). Tracking changes in social relations throughout late life. Journals of Gerontology Series B: Psychological Sciences and Social Sciences 62: 90-99.

Sixsmith, A. \& Sixsmith, J. (2008). Ageing in place in the United Kingdom. Ageing International 32: 3.

Skjaeveland, O. \& Garling, T. (1997). Effects of interactional space on neighbouring. Journal of Environmental Psychology 17: 181-198.

Social Exclusion Unit. (2001). National Strategy for Neighbourhood Renewal. London: Cabinet Office.

Thang, L. L. (2001). Generations in touch: Linking the old and young in a Tokyo neighbourhood. Ithaca, NY: Cornell University Press.

Van Bergeijk, E., Bolt, G. \& Van Kempen, R. (2008). Social cohesion in deprived neighbourhoods in the Netherlands: The effect of the use of neighbourhood facilities. Housing Studies Association Conference, York, UK, 2-4 April 2008.

Völker, B., Flap, H. \& Lindenberg, S. (2007). When are neighbourhoods communities? Community in Dutch neighbourhoods. European Sociological Review 23(1): 99-114. 
Welsh, B. \& Farrington, D. (2008). Effects of improved street lighting on crime. Campbell Systematic Reviews 13: 1-51.

Wiles, J. (2005). Home as a new site of care provision and consumption. In G. J. Andrews \& D. R. Phillips (eds.), Ageing and Place: Perspectives, Policy, Practice (pp. 79-97). New York: Routledge.

Wilkinson, D. (2008). Individual and community factors affecting psychological sense of community, attraction, and neighbouring in rural communities. Canadian Review of Sociology 45(3): 305-329.

Wolf, S. \& Bruhn, J. G. (1993). The power of clan: The influence of human relationships on heart disease. New Jersey: Transaction.

Yang, M.-J., Yang, M.-S., Shih, C.-H. \& Kawachi, I. (2002). Development and validation of an instrument to measure perceived neighbourhood quality in Taiwan. Journal of Epidemiology \& Community Health 56: 492-496.

Ziersch, A. M., Baum, F. E., MacDougall, C. \& Putland, C. (2005). Neighbourhood life and social capital: The implications for health. Social Science and Medicine 60(1): 71-86. 